\title{
Clinically based score predicting cryptogenic NORSE at the early stage of status epilepticus
}

Atsuko Yanagida, MD, Naomi Kanazawa, BS, Juntaro Kaneko, MD, Atsushi Kaneko, MD, Ryoko Iwase, MD, Hiroki Suga, MD, Yutaka Nonoda, MD, PhD, Yuya Onozawa, PhD, Eiji Kitamura, MD, PhD,

Kazutoshi Nishiyama, MD, PhD, and Takahiro lizuka, MD

Neurol Neuroimmunol Neuroinflamm 2020;7:e849. doi:10.1212/NXI.0000000000000849

\section{Abstract}

\section{Objective}

To determine whether a clinically based score predicts cryptogenic new-onset refractory status epilepticus (C-NORSE) at the early stage of status epilepticus (SE) with prominent motor symptoms (SE-M) of unclear etiology.

\section{Methods}

The score (range 0-6) included 6 clinical features: highly refractoriness to antiseizure drugs, previously healthy individual, presence of prodromal fever, absence of prodromal psychobehavioral or memory alterations, absence of dyskinesias, and symmetric brain MRI abnormalities (the first 2 mandatory). We retrospectively assessed the usefulness of a high scale score $(\geq 5)$ in predicting C-NORSE in 83 patients with SE-M of unclear etiology, who underwent testing for neuronal surface antibodies (NS-Abs) between January 2007, and December 2019.

\section{Results}

Thirty-one (37.3\%) patients had a high score. Patients with a high score had more frequent prodromal fever $(28 / 31$ vs $24 / 52)$, mechanical ventilatory support $(31 / 31$ vs $36 / 52)$, and symmetric MRI abnormalities (26/31 vs $12 / 52)$, had less frequent involuntary movements (2/ 31 vs $30 / 52)$, and had absent prodromal psychobehavioral alterations $(0 / 31$ vs $27 / 52)$, CSF oligoclonal band detection ( $0 / 27$ vs $11 / 38)$, tumor association (0/31 vs 13/52), or NS-Abs (0/ 31 vs 29/52) than those with a low score $(<5)$. Thirty-three patients (median age, 27 years; 18 [54.5\%] female) were finally regarded as C-NORSE. The sensitivity and specificity of a high score for predicting C-NORSE were 93.9\% (95\% CI 0.87-0.94) and 100\% (95\% CI 0.95-1.00), respectively.

\section{Conclusions}

Patients with a high score in the indicated scale are more likely to have C-NORSE, making it a useful diagnostic tool at the early stage of SE-M before antibody test results become available.
Correspondence

Dr. lizuka

takahiro@med.kitasato-u.ac.jp

From the Department of Neurology (A.Y., N.K., J.K., A.K., R.I., H.S., E.K., K.N., T.I.) and Department of Pediatrics (Y.N.), Kitasato University School of Medicine; and Department of Clinical Laboratory (Y.O.), Kitasato University Hospital, Sagamihara, Japan. 


\section{Glossary}

$\mathbf{A E}=$ autoimmune encephalitis; AMPAR $=\alpha$-amino-3-hydroxy-5-methyl-4-isoxazolepropionic acid receptor; AQP4 = aquaporin-4; ASD = antiseizure drug; CBA = cell-based assay; C-NORSE = cryptogenic NORSE; DWI = diffusion-weighted image; FC = febrile convulsion; FIRES $=$ febrile infection-related epilepsy syndrome; FLAIR $=$ fluid-attenuated inversion recovery; $\mathbf{G A B A a R}=\gamma$-aminobutyric acid A receptor; $\mathbf{G A B A b R}=\gamma$-aminobutyric acid B receptor; $\mathbf{I g G}=$ immunoglobulin $\mathrm{G}$; IL-6 = interleukin-6; ILAE = International League Against Epilepsy; LGI1 = leucine-rich glioma-inactivated 1; MOG = myelin oligodendrocyte glycoprotein; NCSE = nonconvulsive SE; NMDAR = NMDA receptor; NORSE = new-onset refractory status epilepticus; NS-Abs = neuronal surface antibodies; $\mathbf{O C B}=$ oligoclonal band; $\mathbf{P M H}=$ past medical history; $\mathbf{S E}=$ status epilepticus; SE-M = SE with prominent motor symptoms; $\mathbf{W B C ~}=$ white blood cell.

New-onset refractory status epilepticus (NORSE) is a severe neurologic emergency condition characterized by refractory status epilepticus (SE) without readily identifiable cause in otherwise healthy individuals. ${ }^{1,2}$ The term NORSE is now defined as a clinical presentation, not a specific diagnosis. ${ }^{3}$ When the cause remains unknown despite the extensive workup, it is called cryptogenic NORSE (C-NORSE). ${ }^{2-4}$

According to the consensus definition, NORSE includes patients with viral, paraneoplastic, or autoimmune etiologies ${ }^{3}$; however, it is crucial in clinical practice to differentiate C-NORSE from secondary NORSE with neuronal surface antibodies (NS-Abs) or classical paraneoplastic antineuronal antibodies because treatment strategy and outcome could be different. ${ }^{5}$ A large cohort study reported that a half of 130 patients with NORSE remained cryptogenic, but $37 \%$ were immune mediated; among those, the most common etiology was anti-NMDA receptor (NMDAR) encephalitis. ${ }^{2}$

Although antibody tests are important to determine the etiology, in an emergency condition, it is often difficult to get the antibody test results in appropriate time. Therefore, we previously developed a clinically based score (range 0-6) based on 6 clinical features to predict C-NORSE at the early stage of convulsive SE, which is currently classified into SE with prominent motor symptoms (SE-M) according to the 2015 International League Against Epilepsy (ILAE) criteria for SE. ${ }^{6}$ However, the scale score has not been validated yet. ${ }^{5}$

Here we report the sensitivity and specificity of the high scale score $(\geq 5)$ in predicting C-NORSE at the early stage of SE-M of unclear etiology (before NS-Ab test results are known).

\section{Methods}

\section{Patients selection and antibody assays (study profile)}

We first reviewed the clinical information of 180 patients with seizures of unclear etiology on admission or early stage of seizures, in whom NS-Abs were examined to investigate potential immune-mediated etiologies between January 1, 2007, and December 31, 2019 (figure 1). These patients were admitted to Kitasato University Hospital or other associated hospitals between January 1, 1999, and December 31, 2019; in
7 patients who were admitted before January 1, 2007, archived serum/CSF samples obtained at onset of disease were used for antibody assays.

Then, we selected 129 patients who fulfilled the 2015 ILAE criteria for SE. ${ }^{6}$ Of those, 46 patients with nonconvulsive SE (NCSE) were excluded because the scale score was originally developed to estimate antibody status in patients with convulsive SE. In this study, we included all patients who developed SE-M regardless of refractoriness to conventional antiseizure drug (ASD) treatment. We assessed the sensitivity and specificity of the high scale score $(\geq 5)$ in 83 patients with SE-M of unclear etiology during the early stage.

NS-Abs were measured at the laboratory of Josep Dalmau (University of Barcelona) using both a rat brain immunohistochemistry and cell-based assay $(\mathrm{CBA})^{7-13}$; they included antibodies against the NMDAR, $\alpha$-amino-3-hydroxy-5-methyl4-isoxazolepropionic acid receptor (AMPAR), $\gamma$-aminobutyric acid $B$ receptor (GABAbR), $\gamma$-aminobutyric acid A receptor (GABAaR), metabotropic glutamate receptor 5, dipeptidyl peptidase-like protein 6 , contactin-associated protein-like 2 , leucine-rich glioma-inactivated 1 (LGI1), and neurexin 3. Both serum and CSF were examined in all patients except 4 (only $\operatorname{CSF}[\mathrm{n}=2]$ or serum $[\mathrm{n}=2]$ was available). In addition to NSAbs, myelin oligodendrocyte glycoprotein (MOG) and aquaporin-4 (AQP4) antibodies were examined with $\mathrm{CBA}$ in patients with overlapping encephalitis and demyelinating syndrome $^{14}$ Antibodies against classical paraneoplastic intracellular antigens (CV2/CRMP5, Ma2, Ri, Yo, Hu, GAD65, and amphiphysin) were measured in serum at Kitasato University with EUROLINE (Euroimmun AG) in patients when associated tumor was suspected or those with NORSE criteria.

\section{Criteria for C-NORSE}

Although C-NORSE is not a specific diagnosis, patients were classified into C-NORSE as a subgroup of cryptogenic epileptic syndrome in this study if those fulfilled the following 3 criteria: (1) new-onset refractory SE in previously healthy individual, (2) refractoriness to conventional ASD treatment, and (3) no etiology identified throughout the course of the disease. If the etiology of SE was identified, patients were diagnosed with etiology-based specific diagnosis (e.g., antiNMDAR encephalitis and anti-LGI1 encephalitis). SE was 


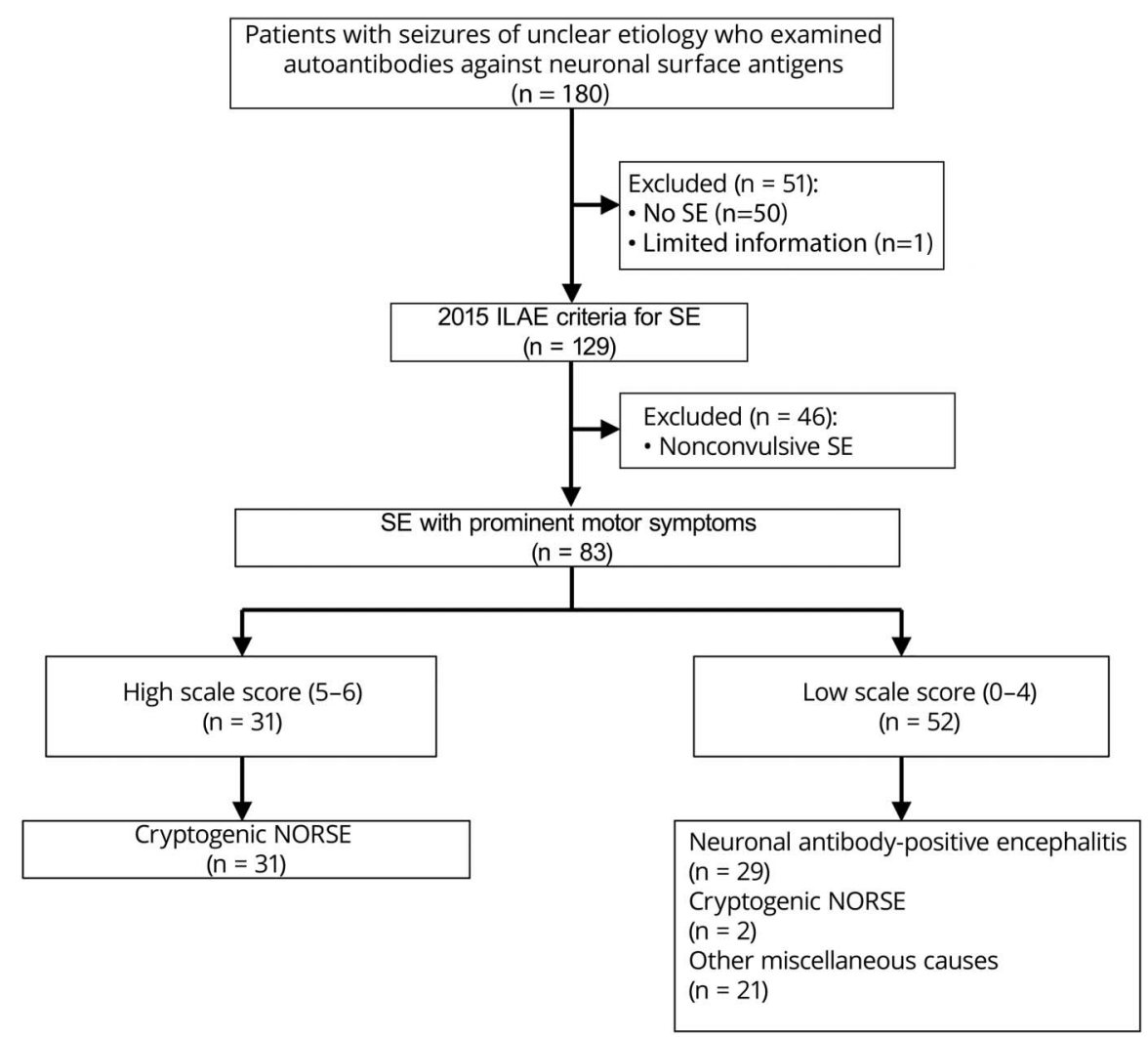

The sensitivity and specificity of the clinically based scale score indicated in the text were assessed among 83 patients with SE with prominent motor symptoms. ILAE = International League Against Epilepsy; NORSE = new-onset refractory status epilepticus; SE = status epilepticus. considered as refractory when it continued longer than 60 minutes despite adequate administration of benzodiazepines and adequate loading of standard IV ASDs. ${ }^{2,6,15,16}$ The etiology of NORSE was extensively investigated with CSF examination, malignancy survey, and serologic testing including autoantibodies against neuronal surface and classical paraneoplastic intracellular antigens.

\section{C-NORSE score}

C-NORSE score is a clinically based score (range 0-6) based on the following 6 clinical features ${ }^{5}$ usually obtained within 14 days after admission in general hospital: (1) NORSE highly resistant to conventional ASD treatment, (2) previously healthy individual before the onset of SE, (3) presence of prodromal high fever of unknown origin before the onset of SE, (4) absence of prodromal psychobehavioral or memory alterations before the onset of SE, (5) absence of sustained orofacial-limb dyskinesias despite a profoundly decreased level of consciousness, and (6) symmetric brain MRI abnormalities (table 1).

In the criteria, we previously defined that each feature represents 1 point, but the first 2 clinical features are mandatory. ${ }^{5}$ Accordingly, if either the first or second feature is absent, the patient is scored 0 . We applied 2015 ILAE criteria for $\mathrm{SE}^{6}$ to include patients with SE-M, and all patients underwent EEG and MRI repeatedly during their hospitalization. However, only patients who had electroencephalographic correlates (such as spikes and waves or periodic discharges that explain prominent motor symptoms) were regarded to meet the first clinical feature of the score. Accordingly, patients without apparent electroencephalographic correlates despite convulsive SE or epilepsia partialis continua were scored 0. Symmetric brain MRI abnormalities imply relatively symmetric increased diffusion-weighted image (DWI) or T2/fluidattenuated inversion recovery (FLAIR) signals in the hippocampus, fimbria, amygdala, claustrum, insula, or perisylvian opercular cortex; these changes may not be seen at the onset of SE-M but often subsequently develop associated with persistent seizure activity. ${ }^{5}$

\section{Clinical assessments}

We assessed the clinical features between patients with a high scale score $(\geq 5)$ and those with a low scale score $(\leq 4)$, including sex, age at onset of SE-M, prodromal fever, prodromal psychobehavioral or memory alterations, involuntary movements, mechanical ventilatory support, CSF and MRI findings, and presence of tumor. We reviewed the final diagnosis of these patients after extensive workup and finally determined the sensitivity and specificity of the indicated high scale score. In this study, to focus on the C-NORSE score, we did not assess the efficacy of treatment, such as immunotherapy, or long-term outcome in these patients. 
Table 1 Components of the C-NORSE score ${ }^{5}$

\begin{tabular}{ll}
\hline Clinical feature & Value \\
\hline 1. New-onset refractory SE highly resistant to conventional ASD treatment & 1 \\
\hline 2. Previously healthy individual before the onset of SE & 1 \\
\hline 3. Presence of prodromal high fever of unknown origin before the onset of SE & 1 \\
\hline 4. Absence of prodromal psychobehavioral or memory alterations before the onset of SE & 1 \\
\hline 5. Absence of sustained orofacial-limb dyskinesias despite profoundly decreased level of consciousness & 1 \\
\hline 6. Symmetric DWI or T2/FLAIR hyperintensities & 1 \\
\hline Total & 6 \\
\hline
\end{tabular}

Abbrevaitions: ASD = antiseizure drug; C-NORSE = cryptogenic new-onset refractory status epilepticus; DWI = diffusion-weighted image; FLAIR = fluidattenuated inversion recovery; $\mathrm{SE}=$ status epilepticus.

C-NORSE score is a clinically based score (range 0-6) based on the above 6 clinical features (slightly modified from the original one ${ }^{5}$ ). In the criteria, each feature represents 1 point, but the first 2 clinical features are mandatory. If either the first or second feature is absent, the patient is scored 0.

In this scale score, refractory SE requires EEG correlates that explain prominent motor symptoms; a patient without EEG correlates is not regarded as CNORSE. The sixth feature means relatively symmetric increased DWI or T2/FLAIR signals in the hippocampus, fimbria, amygdala, claustrum, insula or perisylvian opercular cortex; these changes may not be seen at the onset of SE but often subsequently develop associated with persistent seizure activity. The C-NORSE score should be used only to predict C-NORSE at the early state of SE-M of unclear etiology before antibody test results become available, but it should not be used to make a diagnosis (see Text).

\section{Standard protocol approvals, registrations, and patient consents}

The study was approved by Institutional Review Boards of Kitasato University (B18-193). Written informed consent was obtained from the patients or their family members. Information on symptoms, CSF, MRI, EEG, and treatments was obtained from the authors or referring physicians.

\section{Statistical analysis}

The Fisher exact test was performed for comparison of categorical variables, and the Mann-Whitney test was used for continuous variables. The statistical significance was set at $p<$ 0.05 . The sensitivity and specificity of the high C-NORSE score were determined with 2-way contingency table analysis. We used JMP, version 14 (SAS Institute Inc.), for statistical analyses.

\section{Data availability}

Any data not published within the article are available and will be shared anonymously by request from any qualified investigator.

\section{Results}

\section{Clinical features in patients with a high score and those with a low score}

Of 83 patients, 31 (37.3\%) had a high score (5-6); 17 patients (54.8\%) were female; median age at symptom onset was 27 years (range 5-73 years) (table 2). The remaining 52 patients (62.7\%) had a low score $(0-4) ; 37$ patients $(71.2 \%)$ were female; median age at symptom onset was 25 years (range 10-79 years). Other clinical information is shown in table 2. There was no difference between patients with a high score and low score in female sex and median age at onset. However, patients with a high score had more frequent prodromal fever (28/31 vs $24 / 52)$, mechanical ventilatory support $(31 / 31$ vs $36 / 52$ ), and symmetric DWI or T2/FLAIR hyperintensities (26/31 vs $12 / 52)$ than those with a low score. By contrast, they had less frequent involuntary movements $(2 / 31$ vs $30 / 52)$ and absent prodromal psychobehavioral alterations (0/31 vs 27 / 52), CSF oligoclonal band (OCB) detection ( $0 / 27$ vs $11 / 38)$, tumor association (0/31 vs $13 / 52)$, or NS-Abs (0/31 vs $29 / 52)$ than those with a low score. There was no difference in prodromal headache before the onset of SE, CSF pleocytosis, white blood cell (WBC) counts in CSF, CSF protein levels, or elevated immunoglobulin $\mathrm{G}(\mathrm{IgG})$ index.

\section{Final diagnosis}

Of 83 patients with 2015 ILAE criteria for SE-M $\mathrm{M}^{6}$ of unclear etiology on admission or early stage of SE, 29 (34.9\%) patients were positive for NS-Abs, NMDAR in 26 patients ( 1 with concurrent AQP4 and 1 with MOG), LGI1 in 1, GABAbR in 1, and unknown antigens (not characterized yet) in 1. No AMPAR or GABAaR antibodies were identified. All antibody-positive patients had a low C-NORSE score: 24 patients had 0 , and 5 patients had 3 . The remaining 54 patients $(65.1 \%)$ were negative for NS-Abs; 21 patients were diagnosed with miscellaneous disorders or syndrome including possible autoimmune encephalitis $(\mathrm{AE})^{17}(\mathrm{n}=11)$, autoantibody-negative but probable $\mathrm{AE}^{17}(\mathrm{n}=5)$, antibodynegative autoimmune limbic encephalitis ${ }^{17}(n=1)$, encephalitis associated with systemic lupus erythematosus $(n=2)$, and nonautoimmune neurologic disorders $(\mathrm{n}=2)$. The remaining 33 patients were finally regarded as C-NORSE based on the above criteria (figure 1).

\section{Clinical features of C-NORSE}

Eighteen of 33 patients (54.5\%) were female; median age at onset was 27 years (range 5-73 years). Thirty-one patients 
Table 2 Clinical features in patients with a high score and those with a low score

\begin{tabular}{|c|c|c|c|}
\hline & High score $(n=31)$ & Low score $(n=52)$ & $p$ Value \\
\hline Female sex & $17(54.8 \%)$ & $37(71.2 \%)$ & 0.1574 \\
\hline Median age at symptom onset $(y)$ & $27(5-73)$ & $25(10-79)$ & 0.4916 \\
\hline Prodromal fever of unknown origin ${ }^{a}$ & $28(90.3 \%)$ & $24(46.2 \%)$ & $<0.0001$ \\
\hline Prodromal headache $^{a}$ & $15 / 29(51.7 \%)$ & $23(44.2 \%)$ & 0.6431 \\
\hline Prodromal psychobehavioral or memory alterations ${ }^{a}$ & $0(0.0 \%)$ & 27 (51.9\%) & $<0.0001$ \\
\hline Involuntary movements & $2(6.5 \%)$ & $30(57.7 \%)$ & $<0.0001$ \\
\hline Mechanical ventilatory support & $31(100.0 \%)$ & $36(69.2 \%)$ & 0.0003 \\
\hline Symmetric DWI or T2/FLAIR hyperintensities & $26(83.9 \%)$ & $12(23.1 \%)$ & $<0.0001$ \\
\hline Tumor association & $0(0.0 \%)$ & $13(25.0 \%)$ & 0.0014 \\
\hline CSF pleocytosis (>5 WBCs/ $\mu \mathrm{L}$ ) & $22(71.0 \%)$ & $40(76.9 \%)$ & 0.6063 \\
\hline Median CSF WBC counts (WBCs/ $\mu \mathrm{L}$ ) & $9(1-224)$ & $17(0-279)$ & 0.2188 \\
\hline Median CSF protein (mg/dL) & $41(13-129)$ & $35(14-354)$ & 0.2685 \\
\hline CSF OCB detection & $0 / 27(0.0 \%)$ & $11 / 38(28.9 \%)$ & 0.0017 \\
\hline Elevated IgG index $(\geq 0.74)$ & $2 / 23(8.7 \%)$ & $10 / 38(26.3 \%)$ & 0.1113 \\
\hline NS-Ab detection & $0(0.0 \%)$ & $29(55.8 \%)$ & $<0.0001$ \\
\hline
\end{tabular}

a Prodromal symptoms mean symptoms/signs that developed before the onset of status epilepticus.

Abbrevaitions: DWI = diffusion-weighted image; FLAIR = fluid-attenuated inversion recovery; IgG = immunoglobulin G; NS-Ab = neuronal surface antibody; $\mathrm{OCB}=$ oligoclonal band; $\mathrm{WBC}=$ white blood cell.

(93.9\%) had a high score; 23 patients had 6, and 8 patients had 5 , but 2 patients had a low score (both 4 ). Of interest, 7 of the 33 patients $(21.2 \%)$ had a past medical history (PMH) of febrile convulsion (FC), family history of FC or epilepsy, or both; 3 patients had a PMH of FC (one of them had a family history of FC); 4 patients had no PMH of FC but had a family history of FC $(n=1)$ or epilepsy $(n=3)$.

Prodromal symptoms developed before the onset of SE in 31 of 33 patients ( $93.9 \%)$, fever in 28 of 33 patients ( $84.8 \%)$, and headache in 15 of 31 patients ( 2 unknown). Only 1 patient (3.0\%) developed psychobehavioral alterations before the onset of SE, whereas 3 patients (9.1\%) showed involuntary movements during the course of the disease, but only 1 patient developed sustained dyskinesias mimicking orofaciallimb dyskinesias. All patients required mechanical ventilatory support due to refractory SE.

NS-Abs were not detected in either serum or CSF. Classical paraneoplastic antineuronal antibodies measured in serum in 28 patients were negative but not measured in 5 (no serum was available for examination). CSF examination revealed a median of $9 \mathrm{WBCs} / \mu \mathrm{L}$ (range $0-224 \mathrm{WBCs} / \mu \mathrm{L}$ ) and a median protein level of $41 \mathrm{mg} / \mathrm{dL}$ (range $13-129 \mathrm{mg} / \mathrm{dL}$ ). No CSF-restricted OCBs were detected in 29 examined patients, whereas the $\operatorname{IgG}$ index was elevated in 2 of 25 examined patients $(8.0 \%)$. Ten patients $(30.3 \%)$ had no pleocytosis $(>5$ $\mathrm{WBCs} / \mu \mathrm{L})$. Initial brain MRI was unremarkable in 15 patients (45.5\%), but follow-up MRIs showed abnormal findings in 30 patients (90.9\%); in 27 patients ( $81.8 \%)$, brain MRIs showed symmetric DWI or T2/FLAIR hyperintensities in the medial temporal lobes, basal ganglia, fimbria, claustrum, or perisylvian opercular cortex (figure 2). None of these patients had a tumor identified during the course of the disease.

\section{The sensitivity and specificity of the high C-NORSE score}

The sensitivity and specificity of the high score $(\geq 5)$ for predicting C-NORSE were 93.9\% (95\% CI 0.87-0.94) and 100\% (95\% CI 0.95-1.00), respectively.

\section{Discussion}

This study shows that (1) patients with the high score are more likely to have C-NORSE, (2) the clinically based score C-NORSE score has high sensitivity and specificity for predicting the C-NORSE, and (3) patients with C-NORSE had distinctive clinical features.

In clinical practice, it is important to estimate antibody status in patients with SE of unclear etiology and identify patients with C-NORSE as early as possible because patients with C-NORSE are usually less responsive to first-line immunotherapy ${ }^{4,5}$ and more likely to have poor long-term outcome with cognitive deficits and refractory partial seizures. ${ }^{5}$ 


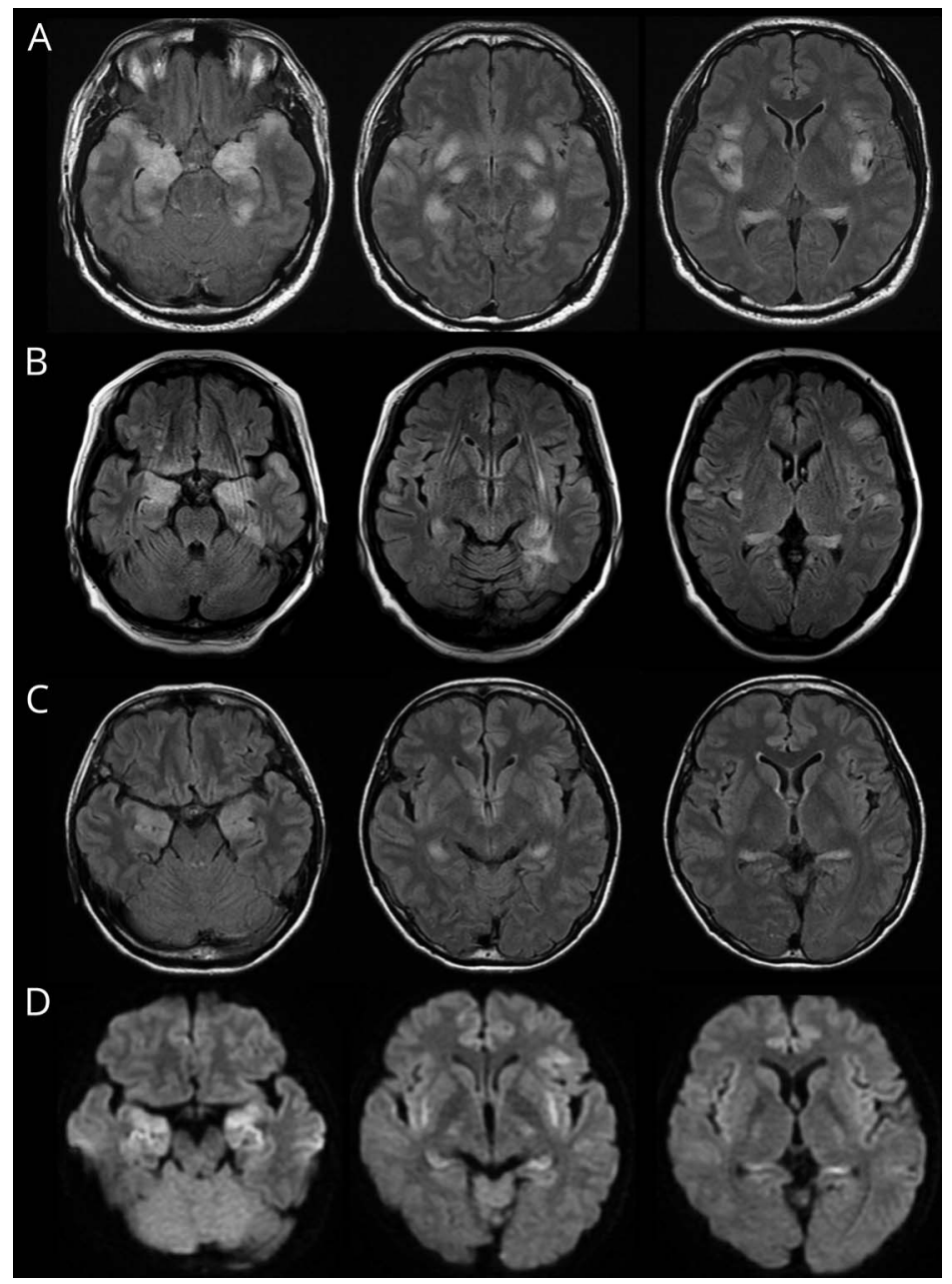

Brain MRIs show symmetric increased DWI or FLAIR signals in the amygdala, hippocampus, fimbria, claustrum, insula, and frontotemporal cortex. Basal ganglia and perisylvian opercular cortex are also involved in patients with C-NORSE (not shown). (A) A 37-yearold man; (B) a 49-year-old woman; (C and D) a 39-year-old woman; (A-C) FLAIR, (D) DWI. C-NORSE = cryptogenic new-onset refractory status epilepticus; DWI = diffusion-weighted image; FLAIR = fluidattenuated inversion recovery.

This scale score was originally developed based on our previous preliminary study ${ }^{5}$ that compared the clinical features of 11 adult patients with C-NORSE (aged $\geq 17$ years) with those of 32 patients with anti-NMDAR encephalitis. We previously reported that the C-NORSE score was higher in patients with C-NORSE than those with anti-NMDAR encephalitis; however, the sensitivity and specificity were not determined. After that, we had recruited additional patients since September 2016. In the meantime, the international consensus definition of NORSE was proposed in $2018^{3}$; hence, the concept of C-NORSE was much more clearly defined than before. In this study, we adopted the concept of C-NORSE and included pediatric cases as well as newly identified adult cases. Accordingly, we increased the number of patients with C-NORSE from 11 to 33 .

In this study, we assessed the sensitivity and specificity of the high score $(\geq 5)$ in 83 patients with SE-M. In this cohort, the sensitivity and specificity for predicting C-NORSE were $93.9 \%$ and $100 \%$, respectively, making it a useful diagnostic tool at the early stage of SE-M of unclear etiology before antibody test results become available.
C-NORSE is a devastating epileptic syndrome of unknown causes, probably of diverse etiologies ${ }^{1-5}$ including autoimmunity, neuroinflammation, or individual susceptibility to seizure. This study highlighted distinctive clinical features of C-NORSE phenotypically different from antibody-positive $\mathrm{AE}$, such as anti-NMDAR, anti-LGI1, or anti-GABAaR encephalitis. Patients with C-NORSE often present with high fever of unknown cause, followed by sudden onset of mainly convulsive seizures, leading to refractory SE (occasionally super-refractory SE) requiring a mechanical ventilatory support and continuous infusion of sedative drugs. Early brain MRI is often normal or may show symmetric DWI or T2/ FLAIR hyperintensities in the medial temporal lobes, ${ }^{5}$ mimicking autoimmune limbic encephalitis. CSF examination often shows nonspecific mild pleocytosis; however, none of these patients had CSF-restricted OCBs, and the IgG index was not elevated in most of them. Of interest, prodromal psychobehavioral or memory alterations usually did not develop before the onset of SE or decreased level of consciousness. This is highly contrast to those with anti-NMDAR encephalitis ${ }^{5,6,17-19}$ or autoimmune limbic encephalitis, ${ }^{17}$ in 
whom these symptoms usually develop in the early course of the disease, and often predominant. Thus, the lack of prodromal psychobehavioral or memory alterations is an important feature in discrimination of C-NORSE from antiNMDAR encephalitis or limbic encephalitis. The follow-up brain MRIs often show symmetric brain lesions involving the hippocampus, amygdala, fimbria, claustrum, basal ganglia, insular cortex, and perisylvian opercular cortex presumably associated with persistent seizure activity. ${ }^{5,20-22}$ Such neuroimaging pattern is quite different from autoimmune limbic encephalitis with highly restricted to bilateral medial temporal lobes ${ }^{17}$ or anti-GABAaR encephalitis with multiple corticosubcortical lesions. ${ }^{13,23}$ Involuntary movements may develop in patients with C-NORSE due to secondary basal ganglia lesions, but not like NMDAR-associated orofacial-limb dyskinesias $^{18}$ or movement disorders, ${ }^{24}$ or LGI1-associated faciobrachial dystonic seizures. ${ }^{25}$

The etiology of C-NORSE remains unknown. ${ }^{1-5}$ It is also controversial whether it is of autoimmune origin. ${ }^{5}$ One might argue that C-NORSE is an epileptic syndrome and should not be confused with $\mathrm{AE}$; randomized controlled trial with immunotherapy has not been conducted yet; therefore, little information is available on the adequate dosage of other immune treatments to formulate any recommendation. ${ }^{3}$ However, it is not easy in clinical practice to exclude a possibility of C-NORSE or antibody-positive AE particularly at the early stage of SE before antibody test results become available; therefore, many patients with NORSE may have been treated with immunotherapy, 5,26 although the first-line immunotherapy is presumed to be less effective. However, if the C-NORSE score is high $(\geq 5)$ on referral from other hospital, it is suggested that the patient is more likely to be negative for neuronal antibodies, thus more likely to be less responsive to first-line immunotherapy and have poor outcome. This scoring strategy might help physicians to identify patients with C-NORSE and their decision making in a patient with the high score.

Although the underlying mechanism of C-NORSE is entirely unknown, inflammation-mediated epileptogenesis has been proposed, ${ }^{27}$ in which a vicious cycle that involves inflammation and seizure activity is assumed to lead to cell death and network reorganization, ultimately causing refractory seizure. One previous study reported high levels of cytokines (interleukin-6 [IL-6]) or chemokines (CXCL10 and IL-8) in serum and CSF in pediatric cases of febrile infection-related epilepsy syndrome (FIRES), ${ }^{28}$ which is currently regarded as a subcategory of NORSE. ${ }^{3}$ Among those, proinflammatory cytokines, such as IL- $1 \beta$ and IL-6, have received attention as potential key molecules in C-NORSE. IL-1 $\beta$ has been implicated in seizure-induced neuronal cell death, ${ }^{29} \mathrm{SE},{ }^{30}$ and posttraumatic epilepsy. ${ }^{31}$ Anakinra, IL-1 receptor antagonist, has been reported to be effective in patients with FIRES. ${ }^{32,33}$ IL-6 secreted from macrophages is also important mediator of fever and its deregulated expression is responsible for development of a variety of autoimmune inflammatory diseases. ${ }^{34}$ The efficacy of tocilizumab, IL-6 receptor antagonist, has also been reported in patients with NORSE. ${ }^{35}$ Therefore, elevated CSF levels of proinflammatory cytokines may play an important role in neuroinflammation, leading to development of refractory partial seizures in NORSE or FIRES. In our cohort of patients with C-NORSE, none of them had autoantibodies binding to the neuronal surface membrane with a rat brain immunohistochemistry in either CSF or serum, indicating that autoantibodies may not play an important role in C-NORSE or FIRES, but rather innate immunity may be more important than adaptive immunity as previously described. $^{5}$

Of interest, $21.2 \%$ of patients with C-NORSE had a PMH of FC, family history of FC, or both. In a small group of patients, some genetic predisposition to epileptic seizure might contribute to development of NORSE following fever. Further research is required to determine a role of genomic susceptibility to NORSE.

This study has limitations of being retrospective studies and based on the small number of patients included. Genomic studies have not been performed yet in our cohort. Classical paraneoplastic antineuronal antibodies were not examined in all patients. Cytokine or chemokines were not examined in either case. In an emergency situation, some of the components of the score may be difficult to assess historically due to a variety of individual factors. A brain MRI is often difficult to obtain in a ventilated patient with SE-M or cannot be performed on a patient with contraindication (e.g., implanted pacemakers, intracranial aneurysm clips, and iron-based metal implants). When early brain MRI is unremarkable, repeated studies are required to see symmetric MRI abnormalities. However, a brain MRI within the first 24 hours is currently included in the diagnostic checklist for etiology of NORSE, ${ }^{36}$ and follow-up MRI is also important in exclusion of alternative diagnosis (multifocal corticosubcortical lesions may appear in the course of the disease in anti-GABAaR encephalitis). It is important to keep in mind that this score was developed in patients with SE-M of unclear etiology. Thus, the results should not be generalized for patients with NCSE.

Despite these limitations, this study demonstrated that the clinically based score is useful for early identification of patients with C-NORSE. However, this score should not be used to make the diagnosis of C-NORSE because NORSE is not a specific diagnosis and exclusion of alternative diagnosis is mandatory. In patients with C-NORSE, irreversible brain damage is expected to occur quickly; thus, early recognition of C-NORSE is crucial. In addition to ASD treatment, we hope that this scoring strategy improves their functional outcome through facilitating early intervention with potential effective drugs that break a vicious cycle of neuroinflammationinduced neuronal damage that consequently increases seizure susceptibility. 


\section{Acknowledgment}

The authors particularly thank Dr. Josep Dalmau (Service of Neurology, IDIBAPS Hospital Clínic, University of Barcelona, Barcelona, Spain) for examining antibodies against neuronal surface antigens and critical comments on this study. They also thank Drs. Hiroki Asari (Shizuoka City Shimizu Hospital), Junya Kaneko (Nippon Medical School Tama Nagayama Hospital), Kenji Yoshida, Kasumi Hattori, and Yuya Itagaki (Fukushima Medical University Hospital), Arifumi Kosakai (Keiyu Hospital), Masashi Watanabe (Ehime Prefectural Central Hospital), Takeo Shishido (Hiroshima University Hospital), Hiroya Ohara (South Nara General Medical Center), Yasushi Hosoi (Hamamatsu University Hospital), Mizuki Ayano (Kyorin University Hospital), Yuka Terasawa (The Jikei University Hospital), Keisuke Imai (Japanese Red Cross Kyoto Daiichi Hospital), and Masamune Sakamoto (Yokohama City University Medical Center) for providing clinical information. They are grateful to all participants and physicians for their contribution to this study.

\section{Study funding}

This study was supported in part by a grant from the Japan Epilepsy Research Foundation (JERFTENKAN 17002, TI).

\section{Disclosure}

A. Yanagida, N. Kanazawa, J. Kaneko, A. Kaneko, R. Iwase, H. Suga, Y. Nonoda, Y. Onozawa, and E. Kitamura report no disclosure. K. Nishiyama received research support from Daiichi Sankyo Co., Ltd., Otsuka Pharmaceutical Co., Ltd., Dainippon Sumitomo Pharma Co., Ltd., and Eisai Co., Ltd. T. lizuka received a grant from The Japan Epilepsy Research Foundation and research support from Astellas Pharma Inc. Go to Neurology.org/NN for full disclosures.

\section{Publication history}

Received by Neurology: Neuroimmunology \& Neuroinflammation April 29, 2020. Accepted in final form May 22, 2020.

Appendix Authors

\begin{tabular}{|c|c|c|}
\hline Name & Location & Contribution \\
\hline $\begin{array}{l}\text { Atsuko } \\
\text { Yanagida, } \\
\text { MD }\end{array}$ & $\begin{array}{l}\text { Kitasato University } \\
\text { School of Medicine, } \\
\text { Sagamihara, Japan }\end{array}$ & $\begin{array}{l}\text { Designed and } \\
\text { conceptualized the study; } \\
\text { acquisition of data; analyzed } \\
\text { and interpreted the data; } \\
\text { and drafted and revised the } \\
\text { manuscript for intellectual } \\
\text { content }\end{array}$ \\
\hline
\end{tabular}

\begin{tabular}{lll}
\hline $\begin{array}{l}\text { Naomi } \\
\text { Kanazawa, } \\
\text { BS }\end{array}$ & $\begin{array}{l}\text { Kitasato University } \\
\text { School of Medicine, } \\
\text { Sagamihara, Japan }\end{array}$ & $\begin{array}{l}\text { Major role in the acquisition } \\
\text { of data; analyzed and } \\
\text { interpreted the data; and } \\
\text { revised the manuscript for } \\
\text { intellectual content }\end{array}$ \\
\hline $\begin{array}{l}\text { Juntaro } \\
\text { Kaneko, MD }\end{array}$ & $\begin{array}{l}\text { Kitasato University } \\
\text { School of Medicine, } \\
\text { Sagamihara, Japan }\end{array}$ & $\begin{array}{l}\text { Major role in the acquisition } \\
\text { of data and interpreted the } \\
\text { data }\end{array}$ \\
\hline $\begin{array}{l}\text { Atsushi } \\
\text { Kaneko, MD }\end{array}$ & $\begin{array}{l}\text { Kitasato University } \\
\text { School of Medicine, } \\
\text { Sagamihara, Japan }\end{array}$ & $\begin{array}{l}\text { Major role in the acquisition } \\
\text { of data and interpreted the } \\
\text { data }\end{array}$ \\
\hline
\end{tabular}

Appendix (continued)

\begin{tabular}{|c|c|c|}
\hline Name & Location & Contribution \\
\hline $\begin{array}{l}\text { Ryoko Iwase, } \\
\text { MD }\end{array}$ & $\begin{array}{l}\text { Kitasato University } \\
\text { School of Medicine, } \\
\text { Sagamihara, Japan }\end{array}$ & $\begin{array}{l}\text { Major role in the acquisition } \\
\text { of data and interpreted the } \\
\text { data }\end{array}$ \\
\hline $\begin{array}{l}\text { Hiroki Suga, } \\
\text { MD }\end{array}$ & $\begin{array}{l}\text { Kitasato University } \\
\text { School of Medicine, } \\
\text { Sagamihara, Japan }\end{array}$ & $\begin{array}{l}\text { Major role in the acquisition } \\
\text { of data and interpreted the } \\
\text { data }\end{array}$ \\
\hline $\begin{array}{l}\text { Yutaka } \\
\text { Nonoda, MD, } \\
\text { PhD }\end{array}$ & $\begin{array}{l}\text { Kitasato University } \\
\text { School of Medicine, } \\
\text { Sagamihara, Japan }\end{array}$ & $\begin{array}{l}\text { Major role in the acquisition } \\
\text { of data and interpreted the } \\
\text { data }\end{array}$ \\
\hline $\begin{array}{l}\text { Yuya } \\
\text { Onozawa, } \\
\text { PhD }\end{array}$ & $\begin{array}{l}\text { Kitasato University } \\
\text { Hospital, Sagamihara, } \\
\text { Japan }\end{array}$ & $\begin{array}{l}\text { Major role in the acquisition } \\
\text { of data and interpreted the } \\
\text { data }\end{array}$ \\
\hline $\begin{array}{l}\text { Eiji } \\
\text { Kitamura, } \\
\text { MD, PhD }\end{array}$ & $\begin{array}{l}\text { Kitasato University } \\
\text { School of Medicine, } \\
\text { Sagamihara, Japan }\end{array}$ & $\begin{array}{l}\text { Major role in the acquisition } \\
\text { of data and interpreted the } \\
\text { data }\end{array}$ \\
\hline $\begin{array}{l}\text { Kazutoshi } \\
\text { Nishiyama, } \\
\text { MD, PhD }\end{array}$ & $\begin{array}{l}\text { Kitasato University } \\
\text { School of Medicine, } \\
\text { Sagamihara, Japan }\end{array}$ & $\begin{array}{l}\text { Major role in the acquisition } \\
\text { of data and interpreted the } \\
\text { data }\end{array}$ \\
\hline $\begin{array}{l}\text { Takahiro } \\
\text { lizuka, MD }\end{array}$ & $\begin{array}{l}\text { Kitasato University } \\
\text { School of Medicine, } \\
\text { Sagamihara, Japan }\end{array}$ & $\begin{array}{l}\text { Designed and } \\
\text { conceptualized the study; } \\
\text { major role in the acquisition } \\
\text { of data; analyzed and } \\
\text { interpreted the data; and } \\
\text { drafted and revised the } \\
\text { manuscript for intellectual } \\
\text { content }\end{array}$ \\
\hline
\end{tabular}

\section{References}

1. Wilder-Smith EP, Lim EC, Teoh HL, et al. The NORSE (new-onset refractory status epilepticus) syndrome: defining a disease entity. Ann Acad Med Singapore 2005;34: 417-420.

2. Gaspard N, Foreman BP, Alvarez V, et al. New-onset refractory status epilepticus: etiology, clinical features, and outcome. Neurology 2015;85:1604-1613.

3. Hirsch LJ, Gaspard N, van Baalen A, et al. Proposed consensus definitions for newonset refractory status epilepticus (NORSE), febrile infection-related epilepsy syndrome (FIRES), and related conditions. Epilepsia 2018;59:739-744.

4. Gaspard N, Hirsch LJ, Sculier C, et al. New-onset refractory status epilepticus (NORSE) and febrile-infection-related epilepsy syndrome (FIRES): state of the art and perspectives. Epilepsia 2018;59:745-752.

5. Iizuka T, Kanazawa N, Kaneko J, et al. Cryptogenic NORSE: its distinctive clinical features and response to immunotherapy. Neurol Neuroimmunol Neuroinflamm 2017;4e:e396. doi: 10.1212/NXI.0000000000000396.

6. Trinka E, Cock H, Hesdorffer D, et al. A definition and classification of status epilepticus-report of the ILAE task force on classification of status epilepticus. Epilepsia 2015;56:1515-1523.

7. Dalmau J, Tüzün E, Wu HY, et al. Paraneoplastic anti-N-methyl-D-aspartate receptor encephalitis associated with ovarian teratoma. Ann Neurol 2007;61:25-36.

8. Lai M, Hughes EG, Peng X, et al. AMPA receptor antibodies in limbic encephalitis alter synaptic receptor location. Ann Neurol 2009;65:424-434.

9. Lancaster E, Lai M, Peng X, et al. Antibodies to the GABA (B) receptor in limbic encephalitis with seizures: case series and characterisation of the antigen. Lancet Neurol 2010;9:67-76.

10. Lai M, Huijbers MG, Lancaster E, et al. Investigation of LGI1 as the antigen in limbic encephalitis previously attributed to potassium channels: a case series. Lancet Neurol 2010;9:776-785.

11. Lancaster E, Huijbers MG, Bar V, et al. Investigations of caspr2, an autoantigen of encephalitis and neuromyotonia. Ann Neurol 2011;69:303-311.

12. Boronat A, Gelfand JM, Gresa-Arribas N, et al. Encephalitis and antibodies to dipeptidyl-peptidase-like protein-6, a subunit of Kv4.2 potassium channels. Ann Neurol 2013;73:120-128.

13. Petit-Pedrol M, Armangue T, Peng X, et al. Encephalitis with refractory seizures, status epilepticus, and antibodies to the GABAA receptor: a case series, characterisation of the antigen, and analysis of the effects of antibodies. Lancet Neurol 2014;13 276-286.

14. Titulaer MJ, Höftberger R, Iizuka T, et al. Overlapping demyelinating syndromes and anti-N-methyl-D-aspartate receptor encephalitis. Ann Neurol 2014;75:411-428.

15. Mayer SA, Claassen J, Lokin J, Mendelsohn F, Dennis LJ, Fitzsimmons BF. Refractory status epilepticus: frequency, risk factors, and impact on outcome. Arch Neurol 2002; 59:205-210. 
16. Brophy GM, Bell R, Claassen J, et al. Guidelines for the evaluation and management of status epilepticus. Neurocrit Care 2012;17:3-23.

17. Graus F, Titulaer JM, Balu R, et al. Clinical approach to diagnosis of autoimmune encephalitis. Lancet Neurol 2016;15:391-404.

18. Iizuka T, Sakai F, Ide T, et al. Anti-NMDA receptor encephalitis in Japan: long-term outcome without tumor removal. Neurology 2008;70:504-511.

19. Dalmau J, Gleichman AJ, Hughes EG, et al. Anti-NMDA-receptor encephalitis: case series and analysis of the effects of antibodies. Lancet Neurol 2008;7:1091-1098.

20. Chevret L, Husson B, Nguefack S, Nehlig A, Bouilleret V. Prolonged refractory status epilepticus with early and persistent restricted hippocampal signal MRI abnormality. J Neurol 2008;255:112-116.

21. Chatzikonstantinou A, Gass A, Förster A, Hennerici MG, Szabo K. Features of acute DWI abnormalities related to status epilepticus. Epilepsy Res 2011;97:45-51.

22. Meletti S, Slonkova J, Mareckova I, et al. Claustrum damage and refractory status epilepticus following febrile illness. Neurology 2015;85:1224-1232.

23. Spatola M, Petit-Pedrol M, Simabukuro MM, et al. Investigations in GABAA receptor antibody-associated encephalitis. Neurology 2017;88:1012-1020.

24. Varley JA, Webb AJS, Balint B, et al. The movement disorder associated with NMDAR antibody-encephalitis is complex and characteristic: an expert video-rating study J Neurol Neurosurg Psychiatry 2019;90:724-726.

25. Irani SR, Michell AW, Lang B, et al. Faciobrachial dystonic seizures precede Lgil antibody limbic encephalitis. Ann Neurol 2011;69:892-900.

26. Gugger JJ, Husari K, Probasco JC, Cervenka MC. New-onset refractory status epilepticus: a retrospective cohort study. Seizure 2020;74:41-48.

27. Nabbout R, Vezzani A, Dulac O, Chiron C. Acute encephalopathy with inflammationmediated status epilepticus. Lancet Neurol 2011;10:99-108.
28. Sakuma H, Tanuma N, Kuki I, Takahashi Y, Shiomi M, Hayashi M. Intrathecal overproduction of proinflammatory cytokines and chemokines in febrile infectionrelated refractory status epilepticus. J Neurol Neurosurg Psychiatry 2015;86:820-822.

29. Medel-Matus JS, Álvarez-Croda DM, Martínez-Quiroz J, Beltrán-Parrazal L, Morgado-Valle C, López-Meraz ML. IL-1 $\beta$ increases necrotic neuronal cell death in the developing rat hippocampus after status epilepticus by activating type I IL-1 receptor (IL-1RI). Int J Dev Neurosci 2014;38:232-240.

30. Tian DS, Peng J, Murugan M, et al. Chemokine CCL2-CCR2 signaling induces neuronal cell death via STAT3 activation and IL-1 $\beta$ production after status epilepticus. J Neurosci 2017;37:7878-7892.

31. Sharma R, Leung WL, Zamani A, O’Brien TJ, Casillas Espinosa PM, Semple BD. Neuroinflammation in post-traumatic epilepsy: pathophysiology and tractable therapeutic targets. Brain Sci 2019;9:318.

32. Kenney-Jung DL, Vezzani A, Kahoud RJ, et al. Febrile infection-related epilepsy syndrome treated with anakinra. Ann Neurol 2016;80:939-945.

33. Westbrook C, Subramaniam T, Seagren RM, et al. Febrile infection-related epilepsy syndrome treated successfully with anakinra in a 21-year-old woman. WMJ 2019;118: 135-139.

34. Kishimoto T, Kang S, Tanaka T. IL-6: a new era for the treatment of autoimmune inflammatory diseases. In: Nakao K, Minato N, Uemoto S, editors. Innovative Medicine: Basic Research and Development [online]. Tokyo: Springer; 2015.

35. Jun JS, Lee ST, Kim R, Chu K, Lee SK. Tocilizumab treatment for new onset refractory status epilepticus. Ann Neurol 2018;84:940-945.

36. Gofton TE, Gaspard N, Hocker SE, Loddenkemper T, Hirsch LJ. New onset refractory status epilepticus research: what is on the horizon? Neurology 2019;92: $802-810$. 


\section{Neurology \\ Neuroimmunology \& Neuroinflammation}

Clinically based score predicting cryptogenic NORSE at the early stage of status epilepticus

Atsuko Yanagida, Naomi Kanazawa, Juntaro Kaneko, et al.

Neurol Neuroimmunol Neuroinflamm 2020;7;

DOI 10.1212/NXI.0000000000000849

This information is current as of July 29, 2020

Neurol Neuroimmunol Neuroinflamm is an official journal of the American Academy of Neurology.

Published since April 2014, it is an open-access, online-only, continuous publication journal. Copyright

Copyright $\odot 2020$ The Author(s). Published by Wolters Kluwer Health, Inc. on behalf of the American

Academy of Neurology.. All rights reserved. Online ISSN: 2332-7812.

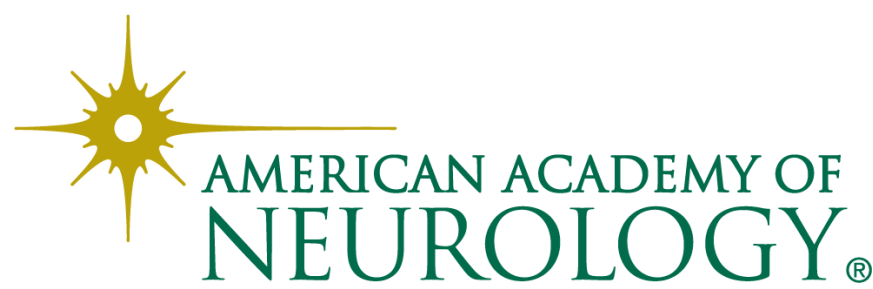




\section{Updated Information \& Services}

References

Citations

Subspecialty Collections

Permissions \& Licensing

Reprints including high resolution figures, can be found at: http://nn.neurology.org/content/7/5/e849.full.html

This article cites 35 articles, 4 of which you can access for free at: http://nn.neurology.org/content/7/5/e849.full.html\#\#ref-list-1

This article has been cited by 1 HighWire-hosted articles: http://nn.neurology.org/content/7/5/e849.full.html\#\#otherarticles

This article, along with others on similar topics, appears in the following collection(s):

All Epilepsy/Seizures

http://nn.neurology.org//cgi/collection/all_epilepsy_seizures Autoimmune diseases

http://nn.neurology.org//cgi/collection/autoimmune_diseases

Encephalitis

http://nn.neurology.org//cgi/collection/encephalitis

MRI

http://nn.neurology.org//cgi/collection/mri

Information about reproducing this article in parts (figures,tables) or in its entirety can be found online at:

http://nn.neurology.org/misc/about.xhtml\#permissions

Information about ordering reprints can be found online:

http://nn.neurology.org/misc/addir.xhtml\#reprintsus

Neurol Neuroimmunol Neuroinflamm is an official journal of the American Academy of Neurology.

Published since April 2014, it is an open-access, online-only, continuous publication journal. Copyright

Copyright $\odot 2020$ The Author(s). Published by Wolters Kluwer Health, Inc. on behalf of the American

Academy of Neurology.. All rights reserved. Online ISSN: 2332-7812.

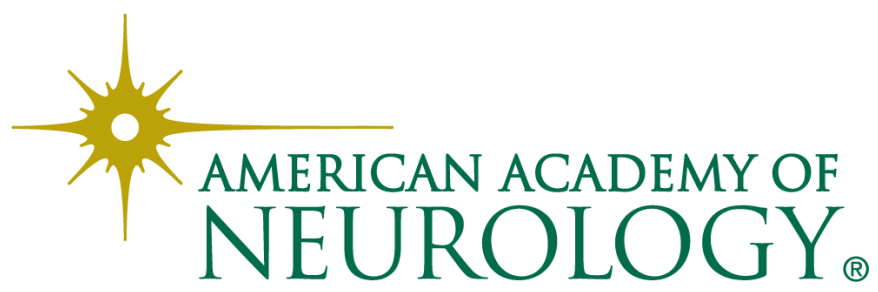

